\title{
The Potential of Using Rubberchips as a Soft Clay Stabilizer Enhancing Agent
}

\author{
Meei-Hoan Ho (Corresponding author) \\ Dept. of Civil and Environmental Engr., Universiti Tun Hussein Onn Malaysia \\ 86400 Parit Raja, Batu Pahat, Johor, Malaysia \\ Tel: 60-16-801-4152_E-mail: homh8@yahoo.com \\ Chee-Ming Chan \\ Dept. of Civil and Environmental Engr., Universiti Tun Hussein Onn Malaysia \\ 86400 Parit Raja, Batu Pahat, Johor, Malaysia \\ E-mail: chan@uthm.edu.my
}

The research is financed by the Postgraduate Incentive Research Grant, Universiti Tun Hussein Onn Malaysia

\begin{abstract}
Soft clays generally display extremely low yield stresses, high compressibility, low strength, low permeability and consequently low quality for construction. Soil stabilization like soil-cement mixing can be effectively adopted to improve the strength and deformation characteristics of the soft clays. To incorporate a 'green' element in the existing stabilization technique, rubber chips derived from waste rubber tyres were used together with cement to stabilized kaolin in the laboratory, exploring the feasibility of the innovative stabilizer. A series of laboratory tests were carried out to study the fundamental mechanical and chemical properties of the cement-rubber chip stabilized kaolin. The mechanical properties examined included bender element and unconfined compressive strength, while the chemical properties included $\mathrm{pH}$ values, conductivity and the percentage of oxide concentration. The overall test results indicated that cement is effective in stabilizing the soils, where significant improvement of unconfined compressive strength $\left(\mathrm{q}_{\mathrm{u}}\right)$ and $\mathrm{P}$ - and S- wave velocities $\left(\mathrm{v}_{\mathrm{p}}\right.$ and $\mathrm{v}_{\mathrm{s}}$ ) were observed. Increasing the percentage of rubber chips alone did not contribute much to strength improvement of the kaolin specimens but are able to increase the percentage of axial strain at failure compared to those specimens without rubber chips. Also, curing time was found to have a significant positive influence on $\mathrm{q}_{\mathrm{u}}, \mathrm{v}_{\mathrm{p}}$ and $\mathrm{v}_{\mathrm{s}}$.
\end{abstract}

Keywords: Soft soil, Cement stabilization, Kaolin, Rubberchips, Bender element, Unconfined compressive strength

\section{Introduction}

In recent decades, the growth of automobile industry and the use of car as the main means of transport have increased greatly the number of tyres produced. This consequently generates a massive stockpile of used tyres. In the early 1990s, research projects were done to reuse tyres in different applications (Ganjian et al., 2008). The recent estimation of tyres stockpiled each year in different countries are as follows, i.e. United States - 300 million (Rubber Manufacturer's Association ,2000), England and Wales - 14 million (Hird et al., 2002), France 10 million (Rubber Manufacturer's Association ,2000), Iran - 10 million (Ganjian et al., 2008), Turkey - 9 million (Unlu, H., 2006) and Malaysia - 1 million (Tung and Hasanan, 2007).

Since waste rubber is not easily biodegradable even after a long period of landfill treatment, material and energy recovery are alternatives to disposal (Segre and Joekes, 2000). On the other hand, a wide variety of waste materials have been suggested as additives to cement-based materials (Naik and Singh, 1991; Siddique and Naik, 2004). Innovative solutions to meet the challenge of tire disposal problem have long been in development. The promising options are: (1) use of tyre in asphaltic concrete mixtures; (2) incineration of tyres for the production of steam and (3) reuse of ground tyre rubber in a number of plastic and rubber products (Paul, 1985).

In Malaysia, for economic reasons, policies for the production of rubber are typically oriented towards benefiting the sizeable rubber industry, which has inadvertently resulted in a considerable problem of waste tires. As a 
counter-measure, the government is encouraging research on sustainable methods of handling the growing problem of rubber waste through various funds and grants.

Stabilization is a process of fundamentally changing the chemical properties of soft soils by adding binders or stabilizers, either in wet or dry conditions, to increase the strength and stiffness of the originally weak soils (Yilmaz and Degirmenci, 2009; Lee and Lee, 2002). Considering the possible negative environmental effects of chemical addition to soils, this study was conducted to explore the possibilities of using cement-rubberchips as a stabilizing agent. The combined admixture was intended to both reduce cost as well as to promote a more environmental-friendly and sustainable stabilizing agent. Kaolin was used as the base clay in the study to minimize variations due to properties of the soil sample itself.

\section{Materials and Methodology}

\subsection{Kaolin}

Kaolin served the purpose of artificial soft clay in this study, and was sourced from Kaolin Malaysia S/B. Physical and chemical properties of the kaolin sample are given in Tables 1 and 2.

\subsection{Rubberchips (RC)}

Rubber chips used in this study were retrieved from discarded used lorries tyre by crushing and removal of the textiles and metal fibers. The rubber chips size are between 2 to $5 \mathrm{~mm}$ in average. It was obtained from Yong Fong Rubber Industries Sdn. Bhd., Malaysia which produces reclaimed rubber such as rubber powder, rubber chips and rubber shreds.

\subsection{Ordinary Portland Cement (OPC)}

Ordinary Portland cement is widely used stabilizer, whether on its own or admixed with other additives. The cement was first oven-dried at $105^{\circ}$ for 24 hours before being stored in airtight containers to maintain the consistency of cement used in the preparation of specimens. Chemical properties of OPC are given in Table 3 (Ho and Chan, 2009). The chemical composition of dry cement is: tricalcium silicates $\mathrm{C}_{3} \mathrm{~S}$, dicalcium silicates $\mathrm{C}_{2} \mathrm{~S}$, tricalcium aluminate $\mathrm{C}_{3} \mathrm{~A}$ and calcium ferroaluminate $\mathrm{C}_{4} \mathrm{AF}$, where $\mathrm{C}=\mathrm{CaO} ; \mathrm{S}=\mathrm{SiO}_{2} ; \mathrm{A}=\mathrm{Al}_{2} \mathrm{O}_{3}$ and $\mathrm{F}=$ $\mathrm{Fe}_{2} \mathrm{O}_{3}$.

\section{Experimental methods \\ 3.1 Preparation of specimens}

The test specimens were prepared by varying the portion of ordinary Portland cement and rubberchips added to kaolin paste of known water content (i.e. $w=50 \%$ ). Analysis was carried out for both mechanical and chemical properties by relating the effects of $0-4 \%$ cement and $0-15 \%$ rubberchips additions, as well as varying curing periods up to a month. These pre-determined percentages of additives were calculated based on dry weight of the kaolin.

The mixture was mixed thoroughly in a mechanical mixer and then compacted in a split mould to form specimens of $38 \mathrm{~mm}$ in diameter and $76 \mathrm{~mm}$ in height. A specially designed miniature hand compaction tool was used to compact the mixture in 4 layers, 50 blows each (Chan, 2006). The extruded specimens were then wrapped in cling films and stored for 28 days prior to testing. The specimens were prepared in pairs as an assurance of the repeatability of specimen preparation method and test procedures.

\subsection{Bender element (BE) test}

The bender element tests were conducted using the GDS Bender Element Test System. The test is essentially a nondestructively test for mechanical wave to test the integrity of concrete structures and to assess cement hydration (Fam and Santamarina, 1996). Evaluation of shear wave $\left(\mathrm{v}_{\mathrm{s}}\right)$ and compression wave $\left(\mathrm{v}_{\mathrm{p}}\right)$ velocities of geomaterials were applied in many geotechnical applications, both in the field and the laboratory (Ismail et al., 2005). These velocities can be used to calculate the small-strain shear modulus $\left(G_{o}\right)$ and constrained modulus $\left(M_{o}\right)$, respectively $G_{o}=v_{s}^{2} \rho$ and $M o=v_{p}^{2} \rho$, where $\rho$ is the bulk density of the tested material.

Changes in the pore fluid affect both double-layer repulsion and van der Walls attraction and therefore, influence shear wave velocity. While the use of P-wave to study cement hydration is not relevant during early stages of hydration since water is the stiffer component. P-waves can be used when the skeleton stiffness exceeds the stiffness of water (Fam and Santamarina, 1996).

The specimen was first placed on the base plate with the transmitting BE engaged in the slot at the bottom end, while the receiving BE was pushed into the slot at the top end of the specimen. As the test does not affect physically the specimens, measurements were carried out on the same specimens at the age of $0,3,7,14$ and 28 
days. In this paper, the relationship between $\mathrm{v}_{\mathrm{s}}$ and $\mathrm{v}_{\mathrm{p}}$ to stiffness were studied.

\subsection{Unconfined compressive strength (UCS) test}

The unconfined compressive strength (UCS) test was conducted according to BS1377-7:1990 (British Standards Institution (BSI), 1990) with the Geocomp LoadTrac II triaxial test machine at a strain rate of $1.0 \mathrm{~mm}$ per minute. Care was taken to ensure that both ends of the specimen were as flat as possible to minimize bedding error during tests, especially with the stiffer specimens. The same specimens subjected to the BE test were tested at 28 days curing. The Young's modulus, E was determined from the stress-strain curve generated in the UCS test. The secantial Young's modulus, $\mathrm{E}_{\mathrm{sec}}$ was derived by taking the gradient from the origin to the peak (i.e. $\mathrm{q}_{\mathrm{u}}$ ) of the plot.

\section{$3.4 \mathrm{pH}$ values and conductivity}

A portable $\mathrm{pH} / \mathrm{EC}$ meter (Hanna multi-parameter meter, HI 991300) was used to determine the $\mathrm{pH}$ values and conductivity of the soil specimen. A $10 \mathrm{~g}$ sample was weighed and diluted with $50 \mathrm{~mL}$ of deionized water. The $\mathrm{pH}$ values and conductivity of the solution were taken for each specimen.

\subsection{X-ray fluorescence $(X R F)$ analysis}

The percentage of oxide concentration of the stabilized materials was examined using the X-Ray Fluorescence (XRF) analysis (XRF Bruker S4 Pioneer). A portion of soil was taken and put into the oven to be dried for 24 hours at $105^{\circ} \mathrm{C}$. The dried sample was then grounded into fine particles passing the $0.063 \mathrm{~mm}$ sieve. However, rubber chips particles in the soil specimens were not able to be broken up or grounded into fine particles.

Hence, loose powder method of specimen preparation was adopted for such samples. The grounded sample was next transferred to a liquid sample holder ( $40 \mathrm{~mm}$ nominal diameter). This double open-ended sample holder enables pre-attachment of thin-film Mylar, which covers the bottom part of the sample holder. Samples were filled through the top opening of the sample holder. The lid of the liquid sample holder was covered with a full-size sleeve before running the test in the test chamber.

\section{Results and Discussions}

Each specimen was labelled using acronyms name, e.g. K0c5RC means kaolin (K) as soft clay, $0 \%$ cement $(0 \mathrm{c})$ and $5 \%$ rubberchips (5RC).

\subsection{Elastic wave velocities}

As shown in Figure 1, the velocities of P-wave $\left(\mathrm{v}_{\mathrm{p}}\right)$ and S-wave $\left(\mathrm{v}_{\mathrm{s}}\right)$ increased with the curing days and cement content. It was observed that the $\mathrm{v}_{\mathrm{p}}$ and $\mathrm{v}_{\mathrm{s}}$ increased over time and eventually reached a plateau after 7 days. This observation reflects the increased stiffness of the stabilized soil due to the hydration of cement with time, whereby it increased significantly in the first 7 days.

The effects of the amount of cement also increased the $v_{p}$ and $v_{s}$, i.e. $2 \%$ cement gave a lower curve line while $4 \%$ cement gave a higher curve line despite the different amount of rubberchips.

A relationship can be established between $v_{p}$ and $v_{s}$ for the 28 -day old specimen, i.e. $v_{p}=0.9137 v_{s}$ as shown in Figure 2. This relationship was observed that $\mathrm{v}_{\mathrm{p}}$ is almost unity to $\mathrm{v}_{\mathrm{s}}$, whereby $\mathrm{v}_{\mathrm{p}} \approx \mathrm{v}_{\mathrm{s}}$. Also, correlation plots between UCS and the wave velocities are given in Figure 3. It can be concluded that basically cementation results in increased strength and stiffness. This phenomena shows that the cement-rubberchips stabilization starts with reduction of water content, then the improvement of physical properties, cement hydration hardening and lastly pozzolanic reaction hardening (in long term) (Kitazume, 2005).

\subsection{Stress-strain relationship}

Figure 4 shows the typical stress-strain curves of the cement-rubberchips stabilized specimens from the UCS tests. Specimens with $4 \%$ cement displayed higher stiffness, as can be observed from the initial section of the curves, and also higher strengths. Looking at the specimens added with cement only, the $2 \%$ and $4 \%$ cement specimens appear to reach post peak strength immediately and then the curves dropped significantly. This behaviour of sudden rupture was very different from the result of (Chan and Ibrahim, 2009). As reported in (Chan and Ibrahim, 2009) which used $5 \%$ and $10 \%$ cement with the same amount of rubberchips. The result showed that the cement-rubberchips admixture was able to maintain certain strength post-yield (i.e. peak strength). It can be concluded that higher amount of cement content will give higher stiffness to the cement-rubberchips stabilized soil.

Rubberchips alone did not contribute much to strength improvement of the soft clay but are able to increase the failure strain compared to those specimen without rubberchips, i.e. specimens $0 \%$ cement for $5 \mathrm{RC}, 10 \mathrm{RC}$ and 
$15 \mathrm{RC}$ is $11.212 \%, 14.236 \%$ and $10.387 \%$ respectively. These specimens have an addition of $3-7 \%$ more failure strain as compared to $2 \%$ and $4 \%$ cement (Figure 4). Therefore, this shows that the rubberchips only specimens will give lower peak strength and a progressive failure. Elasticity of the specimens is directly proportional to rubber content due to the elastic behavior of the rubber.

\subsection{Unconfined compressive strength}

The unconfined compressive strength $\left(\mathrm{q}_{\mathrm{u}}\right)$ is plotted against the percentage of stabilizing agents in Figure 5. Note that the suffix indicates specimen 1 or 2 of the pair. The specimen pairs gave very similar results, pointing to the repeatability of the specimen preparation and the test method, as mentioned in section 3.1.

The original soil registered a low strength of $\mathrm{q}_{\mathrm{u}} \approx 77 \mathrm{kPa}$. The cement-stabilised only specimens, i.e. K2c0RC-1 and $\mathrm{K} 4 \mathrm{c} 0 \mathrm{RC}-1$, recorded $\mathrm{q}_{\mathrm{u}}$ of $130 \mathrm{kPa}$ and $249 \mathrm{kPa}$ respectively, while K2c0RC-2 and K4c0RC-2, recorded $\mathrm{q}_{\mathrm{u}}$ of $177 \mathrm{kPa}$ and $311 \mathrm{kPa}$ respectively. It can be seen that the K2c0RC strength is very similar to that of K2c5RC specimens, suggesting that the effect of $5 \%$ rubberchips addition was negligible on strength improvement of the soil.

The cement-rubberchip stabilized specimens with $4 \%$ cement achieved 2 times higher strengths than those with $2 \%$ cement addition. This observation illustrates the dominant effect of cement as a combined stabilizer with rubberchips. Therefore, it can be concluded that strength increase due to cement-rubberchips is not apparent, when compared with the specimens stabilized with cement only.

Also, with $2 \%$ cement addition, increased quantities of rubberchips did not contribute to significant strength increase, as can be seen in the drop in strength for specimens with $15 \%$ rubberchips. The $4 \%$ cement addition specimens, on the other hand, appeared to reach the highest strength with inclusion of only $5 \%$ rubberchips, suggesting that there could be an optimum mix proportion for the cement-rubberchip admixture as seen in Figure 5 , i.e. $\mathrm{K} 4 \mathrm{c} 10 \mathrm{RC}$ and $\mathrm{K} 4 \mathrm{c} 15 \mathrm{RC}$ dropped in qu.

\subsection{Stiffness}

Stiffness of the specimens was examined based on the secant Young's modulus $\left(E_{\text {sec }}\right)$, taken from origin to the peak strength of a stress-strain plot. In Figure $6, \mathrm{E}_{\mathrm{sec}}$ is plotted with $\mathrm{q}_{\mathrm{u}}$ for all the cement-rubberchips stabilized specimens. The linear correlation was found to yield $\mathrm{E}_{\mathrm{sec}}=48.9 \mathrm{q}_{\mathrm{u}}$, where higher strength specimens displayed higher stiffness too.

Figure 7 shows the relationship between Young's modulus for both shear modulus and constrained modulus. As mentioned in section 3.2, wave velocities were used to obtain the small-strain shear modulus $\left(G_{0}\right)$ and constrained modulus $\left(\mathrm{M}_{\mathrm{o}}\right)$. From this two relationships, a very obvious pattern can be seen, whereby when the cement content increased, $\mathrm{E}, \mathrm{G}_{\mathrm{o}}$ and $\mathrm{M}_{\mathrm{o}}$ also increased. This was due to the changes in the pore fluid in the cement-rubberchips stabilized soil and therefore, influences the S-wave and $\mathrm{G}_{0}$. Similarly, P-wave which influences the $\mathrm{M}_{\mathrm{o}}$ also did increased because the skeleton stiffness of the stabilized soil was formed after 28 days curing. The cement content plays an important role in the increment of $E, G_{o}$ and $M_{o}$, i.e. this relates well with the discussion in section 4.3.

\section{$4.5 \mathrm{pH}$ values and conductivity}

The $\mathrm{pH}$ affects the effectiveness of cement stabilization. The high $\mathrm{pH}$ value of samples containing hydrating cement may attributed to the dissociation of $\mathrm{OH}^{-}$ions from the $\mathrm{Ca}(\mathrm{OH})_{2}$ produced during hydration (Lee and Lee, 2002).

The $\mathrm{pH}$ values of stabilized soil were generally high $(>10)$. $\mathrm{pH}$ value for the original kaolin in this study is 4.55 . It is obvious, as can be seen in Figure 8 that cement, and not rubberchips, contributed to the increment of $\mathrm{pH}$ value in the mixtures. This increase in $\mathrm{pH}$ is due to an increase in the electrolytic concentration of the pore water that results from dissociation of calcium hydroxide (Probaha et al., 2000).

Another significant observation was that the $\mathrm{pH}$ for $2 \%$ cement with different RC (i.e. K2c0RC, K2c10RC and $\mathrm{K} 2 \mathrm{c} 15 \mathrm{RC}$ ) and $4 \%$ cement with different RC (i.e. K4c0RC, K4c10RC and K4c15RC) were very similar to one another, i.e. in a range of 11.53 - 11.81. It can be concluded that rubberchips compound could have leached out some chemical in the water in a very minimal range as seen when no cement was added into the soil. $\mathrm{pH}$ for K0c5RC, K0c10RC and K0c15RC were 5.22, 5.01 and 5.71 respectively. From Figure 8, it can also be observed that there was a drastic change in $\mathrm{pH}$ from cement content of $0 \%$ to $2 \%$, after which the $\mathrm{pH}$ value appeared to be insensitive to the amount of cement added to the clay. The increase in $\mathrm{pH}$ values corresponds with the increased strength measured in the UCS tests (see Figures 5 and 6). $\mathrm{pH}$ must reach a minimum value of 9 to allow cementing reactions to occur (Tremblay et al., 1998). The long term pozzolanic reactions in the 
soil-cement were favored by high $\mathrm{pH}$ values, since the reactions are accelerated due to the solubility of the silicates and aluminates of the clay particles.

A hypothesis of clay cement interaction concluded that a primary and secondary process must be distinguished in the consolidation of the clay-cement mixture. The primary process includes hydrolysis and hydration of cement, in the course of which the usual hydration products appear and the $\mathrm{pH}$ value of the water increases. Hence, $\mathrm{pH}$ remained largely unchanged for cement content $>2 \%$ due to the hydration product from cement. The calcium hydroxide produced in this period and consumed during the course of secondary processes is partly replaced by the lime produced by the cement hydration (Lee and Lee, 2002).

As seen in Figure 9, the conductivity (in milli Siemens) is directly proportional to the different cement content. A linear relationship can be established where $\mathrm{EC}=600 \mathrm{c}-300$. This is because electrical conductivity (EC) varies not only with the concentration of salts (natrium) present, but also the chemical composition of the soil solution (Resh, 2008). In other words, the higher the cement contents in a specimen, the higher the conductivity. Rubberchips do not contribute to the increment of EC, evident in the rubberchips added only specimens (Refer to plot $0 \%$ cement).

It was also observed that conductivity increased with increased $\mathrm{pH}$ values (as shown in Figure 8, corresponding with the increase of oxide concentration in the specimens (Refer to oxide results in Table 4).

\subsection{Oxide concentrations}

Table 4 shows the major oxide concentrations of pure kaolin, cement, rubberchips and the stabilized samples with different rubberchips and cement content. Both $\mathrm{SiO}_{2}$ and $\mathrm{Al}_{2} \mathrm{O}_{3}$ constituted the largest portions in all specimens. This is mainly due to the content of $\mathrm{SiO}_{2}$ which can be found mainly from kaolin and cement hydration. In fact, $\mathrm{SiO}_{2}$ forms the greatest portion in all the specimens, ranging from $50.06 \%$ to $52.20 \%$.

In descending order, the portions of oxide go along trend of $\mathrm{SiO}_{2}>\mathrm{Al}_{2} \mathrm{O}_{3}>\mathrm{CaO}>\mathrm{Fe}_{2} \mathrm{O}_{3}>\mathrm{SO}_{3}>\mathrm{ZnO}$. Therefore, the implication of this concentration trend can determine the amount of oxide concentration that may leach out from the cement-rubberchips specimens from major to minor. Also, $\mathrm{CaO}$ increased when more cement was added (as mentioned in section 2.3). Kaolin, when mixed with cement, would be stabilized because cement and water react to form cementitious calcium silicate and aluminate hydrates, which bind the soil particles together. Hence, the hydration reaction releases calcium hydroxide, $\mathrm{Ca}(\mathrm{OH})_{2}$ or slaked lime, which may in turn react with some components of the soil, in particular clay minerals (Bergado et al., 1996). This theory proved that both $\mathrm{SiO}_{2}$ and $\mathrm{Al}_{2} \mathrm{O}_{3}$ constituted the largest portions in all specimens which mainly contributed by kaolin itself and cement.

The high $\mathrm{pH}$ (in Figure 8) accompanying cement hydration favours the solubility of $\mathrm{SiO}_{2}$ and $\mathrm{Al}_{2} \mathrm{O}_{3}$, which interacts with the $\mathrm{CaO}$ from the hydrated cement and additional cementing material precipitate.

\section{Conclusions}

Following are the main conclusions drawn from this study:

- The velocities of P-waves $\left(\mathrm{v}_{\mathrm{p}}\right)$ and S-waves $\left(\mathrm{v}_{\mathrm{s}}\right)$ increased with curing period and cement content. A plateau was reached after 7 days indicating that the hydration of cement was fully completed in 7 days time causing the stabilized soil increased in stiffness. A relationship was established between $v_{p}$ and $v_{s}$ for specimens aged for 28 days, i.e. $\mathrm{v}_{\mathrm{p}}=0.9137 \mathrm{v}_{\mathrm{s}}$.

- Rubberchips alone did not contribute much to strength improvement of the kaolin specimens but are able to increase the percentage of axial strain compared to those specimen without rubberchips.

- At least $4 \%$ cement addition is required to achieve $\mathrm{q}_{\mathrm{u}}=250 \mathrm{kPa}$, while using only $5 \%$ rubberchips is sufficient and economical in the mix proportion for the cement-rubberchip admixture, i.e. K4c5RC can be a recommended mix.

- $\mathrm{E}_{\mathrm{sec}}$ is approximately 49 times that of $\mathrm{q}_{\mathrm{u}}$ for the kaolin stabilized with cement-rubberchip. While Young's modulus, $\mathrm{E}_{\mathrm{sec}}=0.006 \mathrm{G}_{\mathrm{o}}{ }^{1.454}$ and $\mathrm{E}_{\mathrm{sec}}=0.005 \mathrm{M}_{\mathrm{o}}{ }^{1.434}$ was found in this study.

- Both $\mathrm{pH}$ values and conductivity increased with cement content. Rubberchips is inert to the increment of conductivity.

- Relative values of oxide concentration for kaolin stabilized with cement-rubberchip: $\mathrm{SiO}_{2}>\mathrm{Al}_{2} \mathrm{O}_{3}>$

\section{References} $\mathrm{CaO}>\mathrm{Fe}_{2} \mathrm{O}_{3}>\mathrm{SO}_{3}>\mathrm{ZnO}$.

Bergado, D. T., Anderson, L. R., Miura, N. and Balasubramaniam, A. S. (1996). Soft ground improvement in lowland and other environments. New York: ASCE Press. 234-256 
British Standards Institution (BSI). (1990). BS1377: British Standard Methods of Test for Soils for Civil Engineering Purposes. Part 7: Shear strength tests (total stress)

Chan, C.M. and Ibrahim, K.A. (2009). Ground improvement with cement-rubberchip stabilization. In Karstunen and Leoni (Eds.). Geotechnics of Soft Soils - Focus on Ground Improvement. Taylor \& Francis Group, London, 207-211

Chan, C.M. (2006). A laboratory investigation of shear wave velocity in stabilized soft soils. PhD. thesis. University of Sheffield

Ch'ng, S.S. (2008). S-wave and unconfined compressive strength of cement-palf stabilized kaolin. B. Eng thesis. Universiti Tun Hussein Onn Malaysia

Fam, M.A. and Santamarina, J.C. (1996). Study of clay-cement slurries with mechanical and electromagnetic waves. Journal of Geotechnical Engineering, Vol. 122 (5) 365-372

Ganjian, E., Khorami, M. and Maghsoudi, A.A. (2008). Scrap-tyre-rubber replacement for aggregates and filler in concrete. Construction and Building Materials, 23, 1-9

Hird, A.B., Griffiths, P.J. and Smith, R.A. (2002). Tyre waste and resources management: A mass balance approach. Viridis Report VR2

Ho, M.H. and Chan, C.M. (2009). Chemical effects of cement-stabilised columns on the surrounding soils. The 3rd International Geotechnical Symposium on Disaster Prevention and Reduction, IGS2009. 22-24 July 2009, Harbin, China. 326-333

Ismail, M.A., Sharma, S.S. and Fahey, M. (2005). A small true triaxial apparatus with wave velocity measurement. Geotechnical Testing Journal, Vol. 28 (2) 1-10

Kaolin (M) Sdn Bhd. (2008). [Online] Available: http://www.kaolin.com.my/product.html (26 March 2008)

Kitazume, M. (2005). State of Practice Report: Field and laboratory investigation, properties of binders and stabilised soils. Proceeding of the International Conference on Deep Mixing Best Practice and Recent Advances, Stockholm, Sweden, Vol. 2, 660-684

Lee, K.H. and Lee, S. (2002). Mechanical properties of weakly bonded cement stabilized kaolin. KSCE Journal of Civil Engineering, Vol. 6 (4) 389-398

Naik, T.R. and Singh, S.S. (1991). Utilization of discarded tires as construction materials for transportation facilities. Report No. CBU-1991-02, UWM Center for By-products Utilization, 16

Paul, J. (1985). Encyclopedia of Polymer Science and Engineering 14, 787-802

Probaha, A., Shibuya, S. and Kishida, T. (2000). State of the art in deep mixing technology. Part III: Geomaterials Characterization. Ground Improvement, Vol. 3, 91-110

Resh, H.M. (2008). Hydroponics food production. PhD. [Online] Available: http://www.kaolin.com.my/product.html ( 26 March 2008)

Rubber Manufacturer's Association (2000). Washington, DC.

Segre, N. and Joekes, I. (2000). Use of tire rubber particles as addition to cement paste. Cement and Concrete Research, 30, 1421-1425

Siddique, R. and Naik, T.R. (2004). Properties of concrete containing scrap-tire rubber - an overview. Waste Management, 24, 563-569

Tremblay, H., Leroueil, S. and Locat, J. (1998). Stabilization of clayey soils from Eastern Canada at high water contents. Proceedings of the 3rd International Congress on Environmental Geotechnics, Lisbon, Portugal. 337-340

Tung, C.L. and Hasanan, M.N. (2007) Effect of curing conditions on the compressive strength of crumb rubber concrete paving blocks. World Engineering Congress, Penang, Malaysia, 335-340

Unlu, H. (2006). Recovery of hazardous wastes in automobile industry. Master Thesis: Natural Science Institute of Uludag University, Turkey

Yilmaz, A. and Degirmenci, N. (2009). Possibility of using waste tire rubber and fly ash with Portland cement as construction materials. Waste Management, 29 (5) 1541-1546 
Table 1. Kaolin physical properties (Kaolin (M) Sdn Bhd., 2008)

\begin{tabular}{|c|c|}
\hline Properties & Kaolin \\
\hline Moisture Content & $<7 \%$ \\
pH (30\% solution) & $3.5-6.0$ \\
Brightness & $75 \%-82 \%$ \\
Average Particle Size & $3.0-5.5 \mu \mathrm{m}$ \\
Specific gravity & 2.6 \\
Liquid limit (\%) & $60.5^{*}$ \\
Plastic limit (\%) & $42.5^{*}$ \\
Plasticity index (\%) & $18^{*}$ \\
\hline
\end{tabular}

*conducted by Ch'ng, (2008)

Table 2. Kaolin chemical composition by XRF test

\begin{tabular}{|c|c|}
\hline Formula & Concentration (\%) \\
\hline $\mathrm{SiO}_{2}$ & 54.7 \\
$\mathrm{Al}_{2} \mathrm{O}_{3}$ & 41.2 \\
$\mathrm{~K}_{2} \mathrm{O}$ & 1.83 \\
$\mathrm{Fe}_{2} \mathrm{O}_{3}$ & 0.93 \\
$\mathrm{TiO}_{2}$ & 0.66 \\
\hline
\end{tabular}

Table 3. Chemical properties of ordinary Portland cement by XRF test

\begin{tabular}{|c|c|}
\hline Chemical Composition & Content $(\%)$ \\
\hline Silica $\left(\mathrm{SiO}_{2}\right)$ & 18.30 \\
Alumina $\left(\mathrm{Al}_{2} \mathrm{O}_{3}\right)$ & 4.68 \\
Iron Oxide $\left(\mathrm{Fe}_{2} \mathrm{O}_{3}\right)$ & 2.32 \\
Calcium Oxide $(\mathrm{CaO})$ & 66.80 \\
Magnesium Oxide $(\mathrm{MgO})$ & 1.59 \\
Sodium Oxide $\left(\mathrm{Na}_{2} \mathrm{O}\right)$ & 0.28 \\
Potassium Oxide $\left(\mathrm{K}_{2} \mathrm{O}\right)$ & 0.57 \\
Sulphur Trioxide $\left(\mathrm{SO}_{3}\right)$ & 5.03 \\
Titanium Oxide $\left(\mathrm{TiO}_{2}\right)$ & 0.21 \\
\hline
\end{tabular}


Table 4. Major oxide concentration of the specimens

\begin{tabular}{|c|c|c|c|c|c|c|c|c|c|}
\hline Oxide & \multirow{2}{*}{ Kaolin } & Cement & Rubber & \multicolumn{3}{|c|}{ 2c } & \multicolumn{3}{|c|}{$4 \mathrm{c}$} \\
\cline { 6 - 11 } Concentration & & & Chips & $5 \mathrm{RC}$ & $10 \mathrm{RC}$ & $15 \mathrm{RC}$ & $5 \mathrm{RC}$ & $10 \mathrm{RC}$ & $15 \mathrm{RC}$ \\
\hline $\mathrm{Al}_{2} \mathrm{O}_{3}$ & 41.83 & 4.68 & 16.20 & 40.94 & 41.04 & 39.76 & 40.57 & 39.20 & 39.19 \\
\hline $\mathrm{CaO}$ & 0.21 & 66.80 & 44.87 & 1.87 & 2.02 & 1.97 & 3.23 & 3.24 & 3.31 \\
\hline $\mathrm{Fe}_{2} \mathrm{O}_{3}$ & 1.65 & 2.32 & 1.28 & 1.68 & 1.68 & 1.73 & 1.74 & 1.73 & 1.74 \\
\hline $\mathrm{SiO}_{2}$ & 51.91 & 18.30 & 20.50 & 51.06 & 50.83 & 52.20 & 50.06 & 51.24 & 51.05 \\
\hline $\mathrm{SO}_{3}$ & 0.13 & 5.03 & 6.89 & 0.29 & 0.20 & 0.21 & 0.26 & 0.26 & 0.29 \\
\hline $\mathrm{ZnO}$ & - & - & 6.96 & 0.03 & 0.12 & 0.07 & 0.05 & 0.04 & 0.19 \\
\hline
\end{tabular}
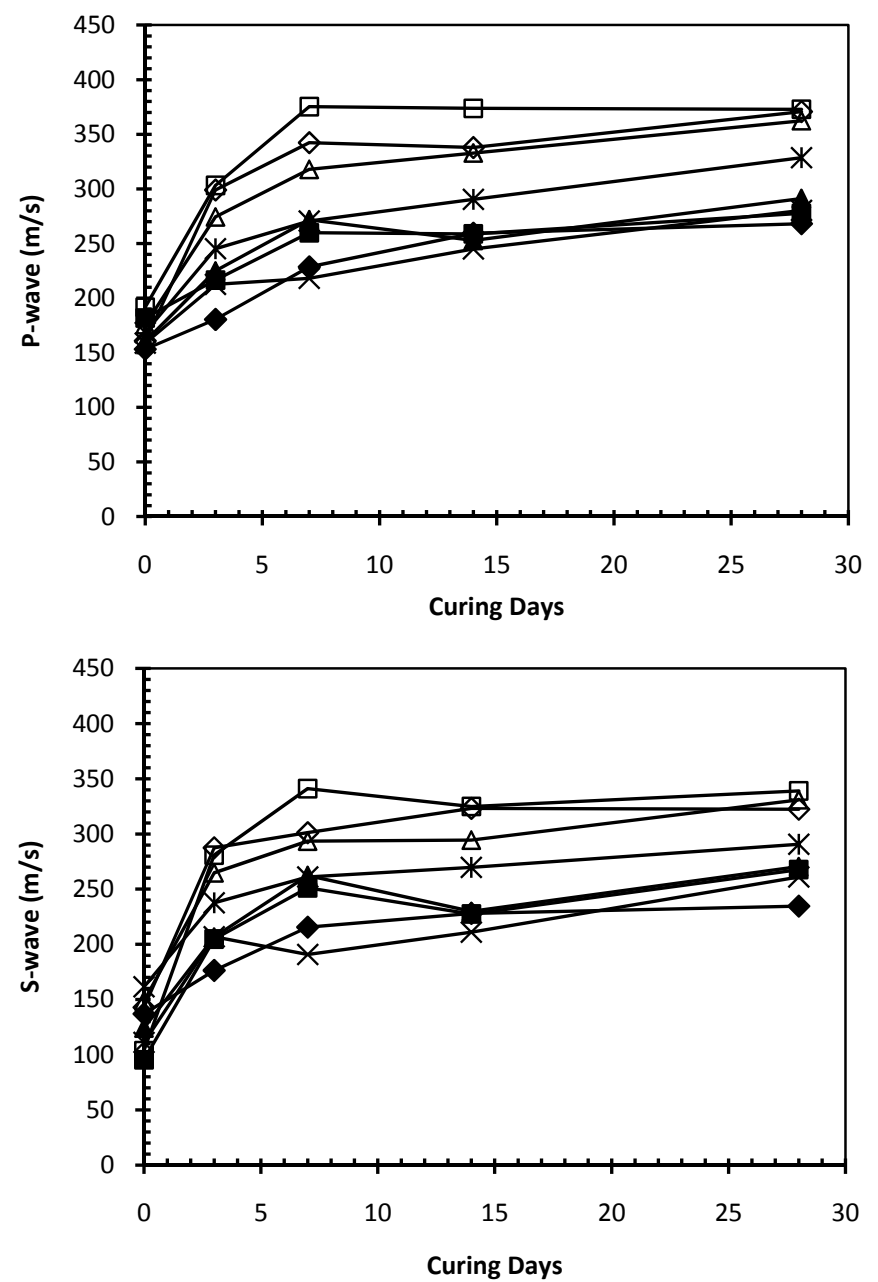

Figure 1. P-wave and S-wave - Curing Days 


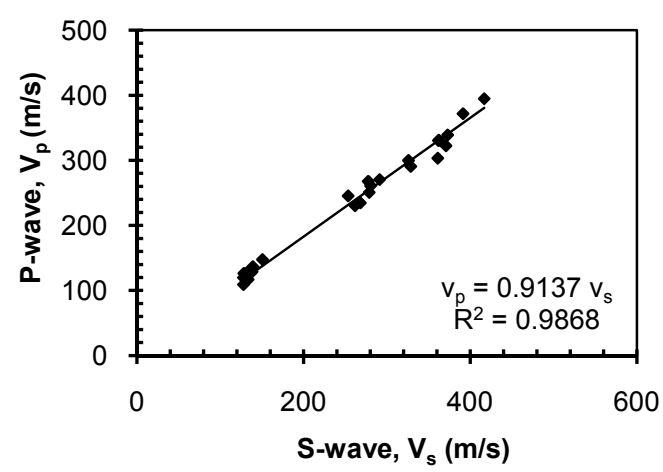

Figure 2. Correlation between $v_{p}$ and $v_{s}$
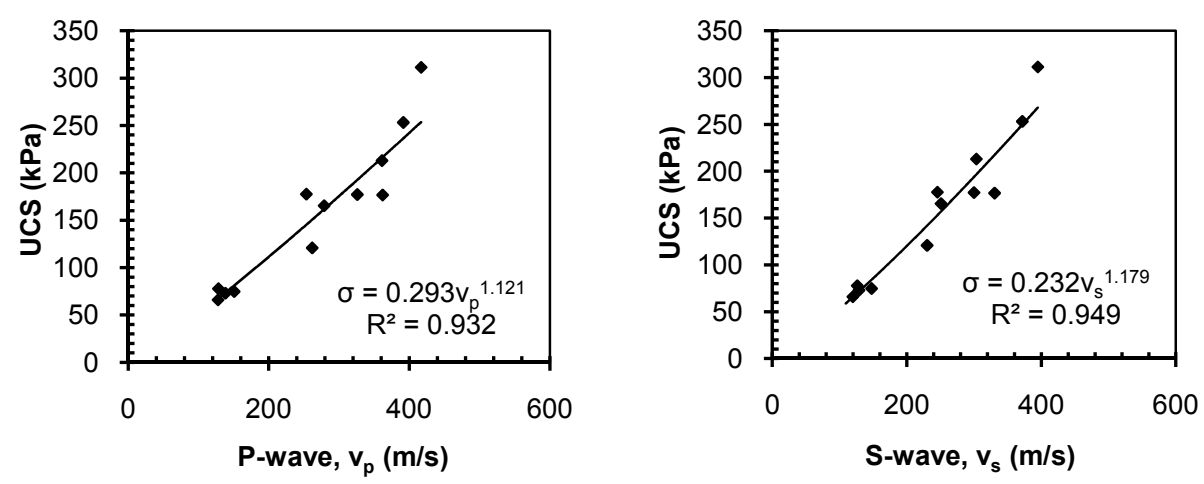

Figure 3. Relatioship between UCS and Wave Velocities
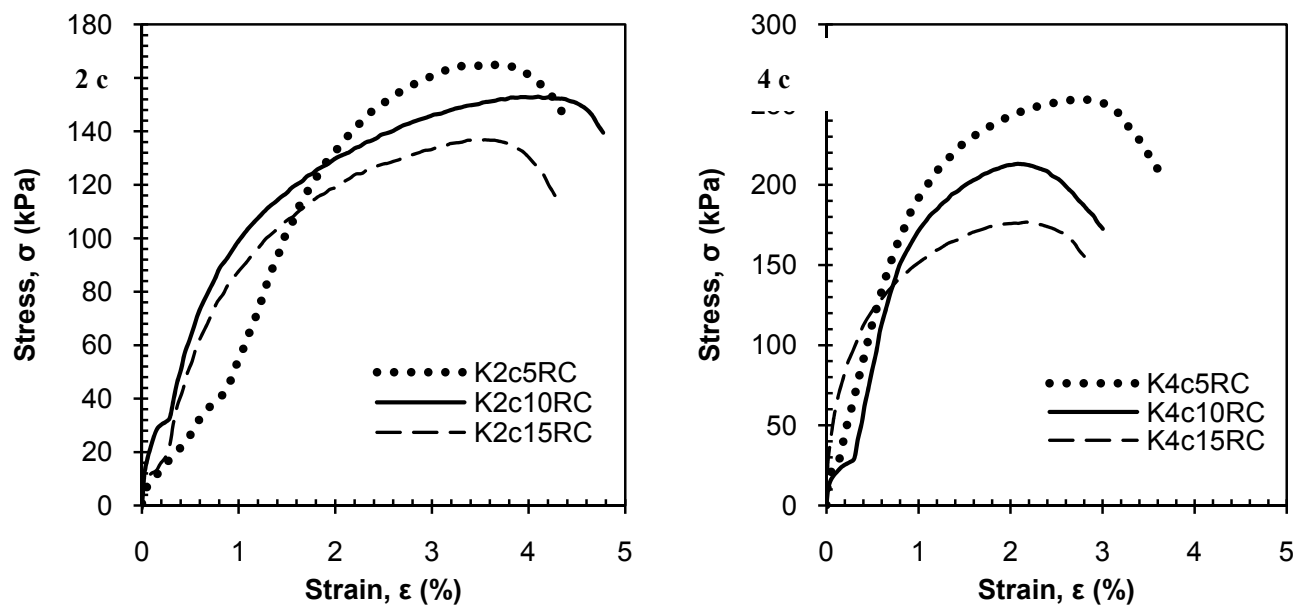

Figure 4. Stress-strain Curves for $2 \%$ and $4 \%$ Cement 


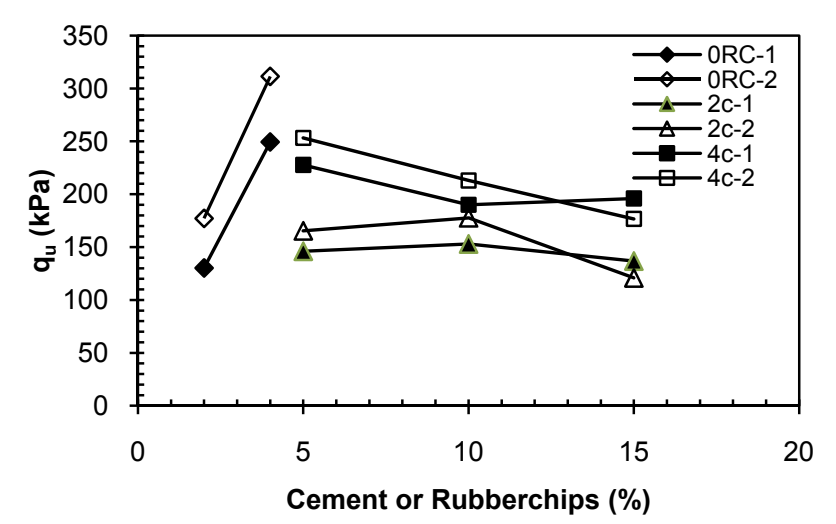

Figure 5. $\mathrm{q}_{\mathrm{u}}-$ Cement or Rubberchips

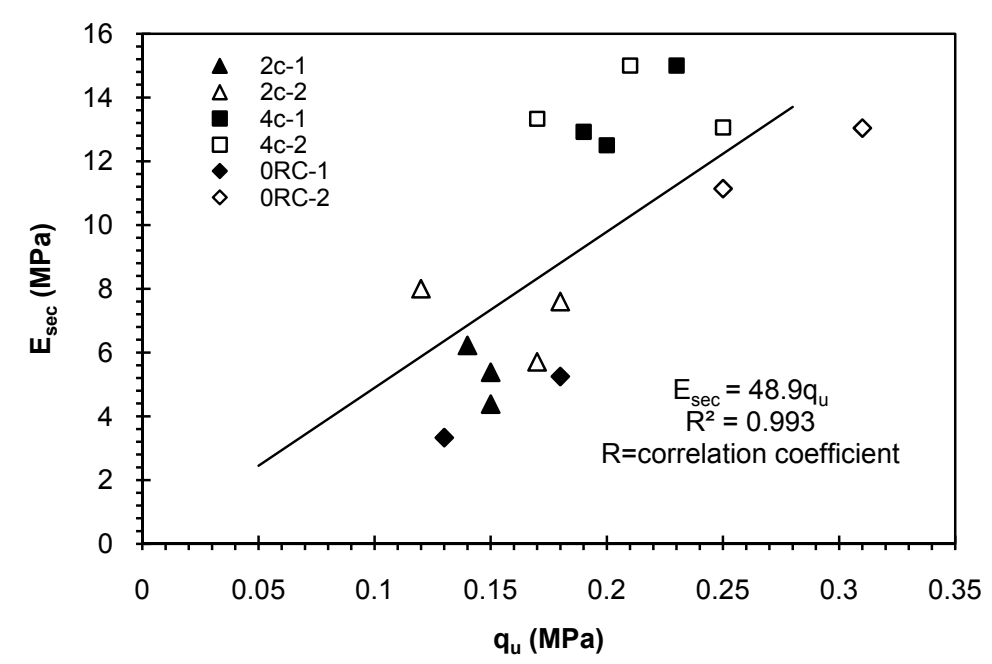

Figure 6. $E_{s e c}-q_{u}$
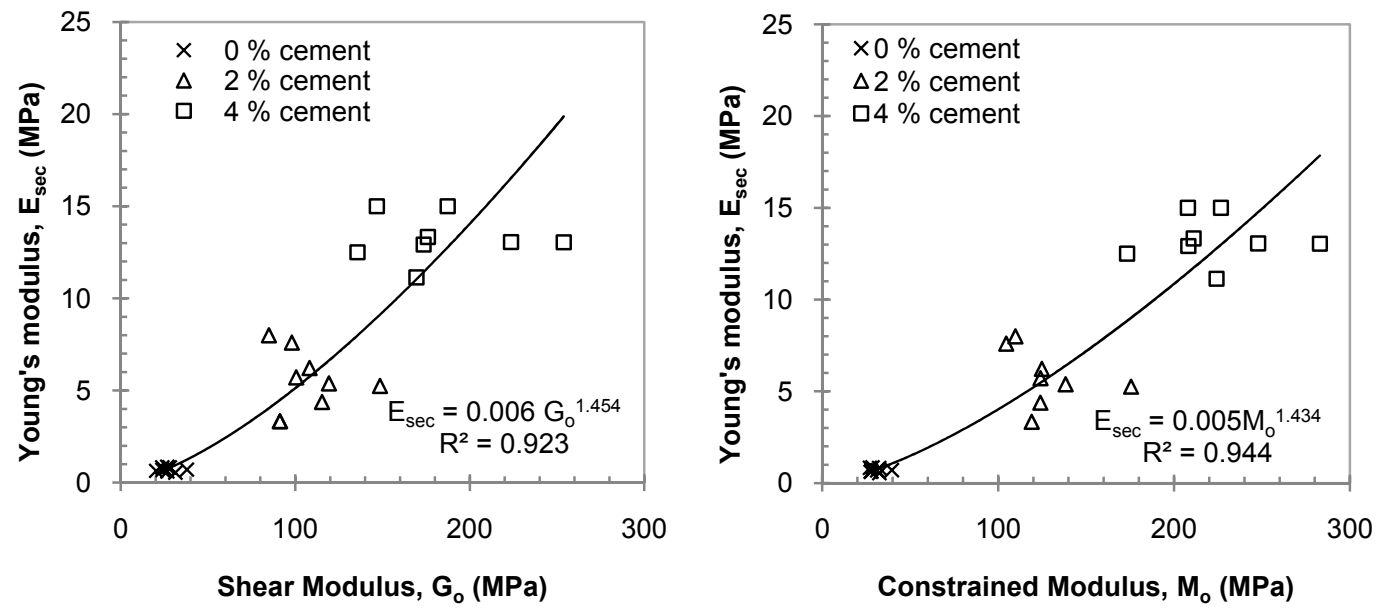

Figure 7. $E_{\mathrm{sec}}-\mathrm{G}_{\mathrm{o}}$ and $\mathrm{M}_{\mathrm{o}}$ 